\title{
Mulheres rurais: o deslocamento da atenção de ocupar-se de si no tempo de lazer para cuidar do outro
}

\author{
Naira Leticia Giongo Mendes Pinheiro' \\ Maria Simone Vione Schwengber ${ }^{2}$ \\ Fernando Jaime González $z^{3}$
}

\section{RESUMO}

Nos últimos tempos, o lazer funda uma nova moral de promessa, bem-estar, felicidade, saúde, segurança. Desse modo, buscamos compreender, a partir de trajetórias de mulheres rurais, como elas constroem suas experiências no tempo de lazer, na teia do cuidado de si e das sociabilidades. A pesquisa de campo dá-se no município de Jóia, estado do Rio Grande do Sul. Das análises que resultaram desta investigação, salta-nos aos olhos o fato de que as mulheres, no início, nos perguntavam: "o que é lazer exatamente?". Tomamos essa indagação como um pedido de direito de mais informação, mas aos poucos começamos a entender que o lazer do adulto e, mais ainda, dessas mulheres rurais tem sido uma dimensão vivida com parcas possibilidades. Focalizamos um movimento que denominamos posição de deslocamento, em que as mulheres deslocam sua atenção de cuidar de si, de ocupar-se de si no tempo de lazer, para cuidar do Outro.

Palavras-chave: Cuidado de si. Mulheres. Lazer.

1 Mestre em Educação nas Ciências. Universidade Regional do Noroeste do Estado do Rio Grande do Sul (UNIJUÍ). ljuí/Rio Grande so Sul, Brasil. E-mail: nairaleticiagmendespinheiro@gmail.com

2 Doutora em Educação. Professora do Programa de Pós-Graduação Mestrado e Doutorado em Educação nas Ciências da Universidade Regional do Noroeste do Estado do Rio Grande do Sul (UNIJUí). ljuí/Rio Grande do Sul, Brasil. E-mail: simone@unijui.edu.br

3 Doutor em Ciências do Movimento Humano. Professor do Programa de Pós-Graduação Mestrado e Doutorado em Educação nas Ciências da Universidade Regional do Noroeste do Estado do Rio Grande do Sul (UNIJUÍ). E-mail: fjg@unijui.edu.br

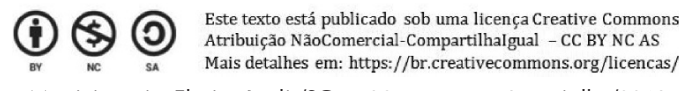


Rural women and leisure experiences: displacement of the self towards the other's life and need

\begin{abstract}
Lately, leisure establishes a new moral of promise, welfare, happiness, health, security. This way, we seek to understand, from rural women trajectories, how they construct their experiences in leisure time, in the net of responsibilities and self-care. This research was set in the town of Joia, in the state of Rio Grande do Sul. From the analysis that resulted from this investigation, it is clear to us the fact that women have asked us initially: "What is leisure, exactly?". We have taken those inquiries as a request for more information, but, gradually, we started to understand that the leisure of adults and, even more, of those women, has been a dimension lived with scarce possibilities. We focused on a movement that we named displacement position, in which women displace their attention from caring for themselves and occupying themselves with themselves in the leisure time, to take care for the Other.
\end{abstract}

Keywords: Self-care. Women. Leisure.

Mujeres rurales y experiencias de ocio: es desplazamiento de si para la vida y necesidad del otro

\title{
RESUMEN
}

Buscamos comprender, a partir de trayectorias de mujeres rurales, como ellas construyen sus experiencias en el tiempo de ocio, en la tela del cuidado de si mismo y de las sociabilidades. La búsqueda de campo se da en la ciudad de Jóia, provincia del Rio Grande do Sul. De las análisis que resultaron de esa investigación, nos salta a los ojos el facto de que las mujeres, en el inicio, nos preguntaban: "qué es ocio exactamente?". Tomamos esas indagaciones como un pedido de derecho de más información, pero a los pocos empezamos a entender que el ocio del adulto y, aún, de esas mujeres rurales hay sido una dimensión vivida con parcas posibilidades. Focalizamos un movimiento que denominamos posición de desplazamiento, en que las mujeres desplazan su atención de cuidar de si, de ocuparse de si en el tiempo de ocio, para cuidar del otro.

Palabras clave: Cuidado de si. Mujeres. Ocio. 


\section{PALAVRAS INICIAIS}

Este artigo coloca em análise as experiências de lazer como forma de cuidado de si. A reflexão aqui objetiva compreender os contornos que as experiências de lazer assumem na articulação com o cuidado de si (FOUCAULT, 2004). As experiências ${ }^{4}$ de lazer possuem sentido singular em cada cultura, pois estão de algum modo vinculadas aos diversos significados sociais e históricos e aos processos que delimitam e diferenciam no tempo e nos espaços. Como nos ensina Foucault (2003), cada experiência se produz a partir de fluxos discursivos que podem ser práticas de si. Utilizamos essa noção proposta por Foucault (2003) como ferramenta teórica/metodológica para pensar aqui as experiências de lazer, afirmando que, de alguma maneira, elas estão assinaladas pela formação histórica que as constitui. As práticas sociais são constituídas por discursos, que, para Foucault (2003), são produzidos mediante as relações de saber-poder que se instituem por meio de regimes de verdades, e são elaboradas por intermédio de ações.

Buscamos, a seguir, inventariar algumas das condições de emergência que possibilitaram a instauração de um "campo de saber" (FOUCAULT, 2003) denominado lazer, inicialmente circunscrevendo-o em alguns contextos, na direção de dar visibilidade às condições de sua emergência.

O campo dos estudos de lazer não é uniforme, apresentando, ao contrário, disparidades, confrontações e descontinuidades teóricas. O próprio termo "lazer", a partir das contribuições das Ciências Humanas e Sociais, é dificilmente percebível como um bloco uno. Problematizar as condições de emergência de determinados significados e de práticas que convivem conosco hoje é circunscrever e reconhecer algumas ordens de discursos em que o campo do lazer se tornou possível e tem sido tomado como um campo de verdade(s) (FOUCAULT, 2003).

Na próxima seção, optamos por um caminho que discute, inicialmente, as transformações que as experiências discursivas de lazer sofreram, de acordo com alguns marcadores temporais.

\section{Lazer na ordem dos discursos}

Para algumas sociedades, como a primitiva, o tempo de lazer fazia parte da vida coletiva e aparecia como um momento de reafirmação de coesão social. Tanto o lazer quanto os rituais religiosos eram práticas que fortaleciam os laços e sentimentos de pertença. As práticas discursivas de lazer estavam associadas às demais ações sociais cotidianas. As atividades de lazer, tais como os jogos, as danças e os rituais religiosos, "serviam de pretexto para festa" (HUIZINGA, 2007, p. 25).

4 Tomamos a noção de experiência a partir das contribuições de Foucault (2003). Quando Foucault se pergunta como seres humanos se tornaram (historicamente) sujeitos, mostra a maneira como fomos (e somos) subjetivados a partir de uma série de discursos, instituições, estruturas espaciais arquitetônicas, leis, enunciados científicos e religiosos, proposições morais e filantrópicas. Em outras palavras, aponta como, a partir desses "dispositvos", foi (é) possível uma determinada "experiência de si", o que envolve modos historicamente peculiares de se fazerem "ferramentas para fabricação" - tecnologias do eu. A experiência de si se apresenta numa contingência histórica e cultural (LARROSA, 2000). 
No mundo helênico, as danças, músicas, poesias e brincadeiras também eram consideradas um núcleo central da vida social. Nessa sociedade, "entre o tempo de trabalho e o tempo sem trabalho, não havia ainda distinção" (CORBIN, 2001, p. 11); as duas categorias agiam em interação. O lazer como instância distinta e específica da vida social começou a ser vivido com mais potência a partir do advento da Revolução Industrial. ${ }^{5}$ Assim, a ética do trabalho foi ganhando cada vez mais força, e o tempo do lazer passou a ser considerado o tempo que ficou disponível depois das atividades do trabalho (CORBIN, 2001).

Dumazedier (2001) destaca o lazer como uma criação das sociedades modernas, associado ao movimento de urbanização e de industrialização. Para o autor, as atividades de lazer cada vez mais se opunham às obrigações do mundo do trabalho. Nessa perspectiva, o lazer é compreendido a partir de um contexto histórico em que se processa a separação entre os tempos e os espaços das atividades individuais, intelectuais, familiares, comunitárias e políticas como base na separação tanto do tempo quanto do espaço. O lazer moderno aparece como um aspecto histórico "do não trabalho".

Na trilha das histórias sobre as experiências de práticas de lazer, vários discursos foram pronunciados. Alguns deles, a partir da modernidade, associam o lazer a uma dimensão funcionalista. O lazer é visto como:

\section{[...] busca da "paz social", da manutenção da "ordem".}

[...] instrumentalizando um recurso para o ajustamento das pessoas a uma sociedade supostamente harmoniosa, ou fator que ajuda a suportar a disciplina e as imposições sociais e a ocupar o tempo com atividades equilibradas e corretas do ponto de vista "moral"(MARCELLINO, 2002, p. 48).

Assim, temos a impressão de que, em determinados períodos históricos, as práticas de experiências de lazer também se prestaram para regular, controlar e disciplinar homens e mulheres para certo modelo de sociedade, para certo projeto civilizatório (ELIAS, 1993).

A contemporaneidade, sobretudo na cultura ocidental, tem enfocado as práticas de experiência corporal com veemência, enfatizando o autogoverno dos corpos e o autocuidado por meio também das experiências das práticas de lazer como um dos elementos de "autonomia e sucesso, contribuindo na formação de matrizes identitárias, como a constituição de sujeitos ativos". ${ }^{6}$ Parece que é nesse marco histórico que, na sociedade

5 As classes populares criaram diferentes estratégias de resistência às restrições ao direito do lazer (CORBIN, 2001)

6 No Brasil, Sant'Anna (1994) destaca que o Esporte para Todos (EPT) surgiu, a partir de 1973, eivado de pressupostos filosóficos que propunham a democratização das atividades físicas e desportivas. Destaca a autora que, nessa década, um evento de impacto em favor da mobilização da população foi realizado pela Rede Globo sob o nome de "Mexa-se", que coincidiu com a copa do mundo de 1970 e com a elaboração do Plano Nacional de Educação Física e Desportos - PNDE, 1976 -, tendo como objetivos principais aprimorar a aptidão física da população, elevar o nível do desporto em todas as áreas, intensificando a sua prática nas massas, ampliar o nível técnico das representações nacionais e difundir as atividades esportivas como forma de utilização do tempo de lazer. O esporte, nesse sentido, não se restringiria apenas aos praticantes dotados de habilidades motoras, com o intuito de estabelecer uma seleção entre os esportistas e os não-esportistas, passando a ser, a partir daquele momento, um elemento acessível a toda a população, independentemente do estágio de capacidade física em que se encontravam os indivíduos (SANT'ANNA, 1994). 
brasileira, as prescrições das experiências das práticas de lazer a partir da segunda década do século 20 se popularizaram, como afirma Sant'Anna (1994). Os canais midiáticos, como programas de rádio, TV, novelas, programas de auditório, revistas, computador, internet, redes sociais, cadernos de bem-estar e livros de autoajuda, passam a dar uma maior valorização ao lazer como um dos receituários da dita "qualidade" de vida e, ainda, de promoção de bem-estar social.

Foucault (1999) ajuda-nos a pensar o quanto se cria, a partir da modernidade, em campo de experiência de práticas de si; aqui pensamos o das práticas de lazer, com a liberdade de opção, qual seja, aquela que se relaciona com os jogos do bem-estar e dos dispositivos de segurança. Foucault (2008) destaca ser a segurança um movimento que avança como racionalidade de governo dos indivíduos e das populações. Tal estado de governo tem como alvo os indivíduos e as populações e utiliza a instrumentalização de um conjunto de saberes, o que corresponde a uma sociedade controlada por dispositivos de segurança (FOUCAULT, 2008). Desde então, passamos a viver cada vez mais em uma sociedade que se estrutura por dispositivos de segurança que se associam com a coexistência de uma sociedade de direitos ${ }^{7}$.

O lazer como direito social foi incluído na Constituição Brasileira pela primeira vez em 1988. O lazer passa, então, a ser requerido como "direito fundamental" e como "necessidade básica dos cidadãos", 8 no caso aqui, dos brasileiros. Essa forma de compreender as experiências de lazer como direito e como promessa de proteção dos indivíduos e da coletividade parece que é o que os prende no interior dos dispositivos de governo e de segurança presentes na sociedade contemporânea do bem-estar social. ${ }^{9}$

Para Candiotto (2011, p. 4), a racionalidade faz do estado de bem-estar a nova configuração da dupla face da biopolítica (expressão cunhada por Foucault, 2003b), que é a "consolidação de um novo pacto de segurança entre as instituições políticas e os cidadãos". Parece que as experiências contemporâneas de lazer se tornaram mais um dos dispositivos de seguridade.

O saber, no caso das práticas de lazer, tem efeito de poder. Nas palavras de Foucault (2006, p. 142), governar, no caso, significa "uma prática social de sujeitar os indivíduos por mecanismos de saber-poder que proclamam uma verdade". Assim, entendemos que a produção de sujeitos ativos demanda processos históricos, formas de saber-poder que circulam na vida cotidiana, marcando os sujeitos, impondo jogos de verdades - aqui, o das experiências de lazer - nos quais os sujeitos são sensibilizados a reconhecer-se.

Nessa dispersão histórica e em movimento das experiências de lazer, consideramos oportuno aproximarmo-nos do pensamento foucaultiano, mais especificamente, do terceiro

7 Para Foucault (2008), os direitos humanos não têm apenas a função emancipatória, como pensado geralmente pelos juristas, mas cumpre funções de controle e de regulação da vida.

8 Fimyar (2009) destaca esse duplo movimento da formação do Estado moderno: o da construção da subjetividade de seus partícipes, convertidos em cidadãos, e os esforços dos sujeitos governáveis por meio do controle, da normalização e da condução das condutas.

9 Para Candiotto (2011), a expressão de bem-estar como atribuição do Estado é cunhada e ganha força a partir das duas grandes guerras. O Estado trata, a partir daí, de evitar a morte e de fazer viver e encarrega-se de cuidar da vida, garantindo acesso à educação, saúde, moradia, lazer e cultura. 
percurso, cuidado de si, cuja noção do processo de subjetivação ${ }^{10}$ do ponto de vista do "governo da vida" e de poder não está vinculada somente à ação exercida sobre um corpo com a finalidade de discipliná-lo, mas sim sobre a ação de si que conduz a partir de práticas de si. Nesse deslocamento, o sujeito não é visto como docilizado, passivo e dominado, cedendo espaço ao sujeito ativo que é capaz de práticas de si. Assim, a liberdade de ação é condição para essa especificidade do governo de si. No entendimento de Foucault (2004, p. 268), "para vivenciar a liberdade, era necessário se ocupar de si mesmo, cuidar de si", ou seja, assumir-se eticamente diante da vida.

O percurso teórico-metodológico analisado neste artigo constitui-se na aproximação com as concepções foucaultianas sobre cuidado de si, práticas de si e experiência de liberdade, elementos que entendemos serem chaves para compreender a capilarização dos discursos de cuidado de si. Tensionamos as experiências das práticas de lazer de um grupo de mulheres rurais que servirão de referências empíricas das considerações analíticas aqui realizadas.

Na próxima seção, situamos o debate teórico dos conceitos cuidado de si, práticas de si e experiência de liberdade, de Michel Foucault.

\section{Cuidado de si, práticas de si como experiência de liberdade}

Foucault (2004), no seu terceiro movimento, passa a problematizar os processos de subjetivação do ponto de vista do governo de si, do cuidado de si. Dedica-se a estudar a constituição dos sujeitos na sua relação consigo e com os outros e o tema da conduta da vida. Parte da história do presente, uma vez que estava incomodado com a ética normativa da Modernidade ${ }^{11}$. Nessa perspectiva, desqualifica a noção do cuidado de si, do "ocupa-te com a dimensão da vida, e ganha força o conheça-te a ti mesmo", reduzindo o cuidado de si a um organicismo (um reducionismo biologizante da esfera corporal) que se espraia na contemporaneidade. Para Foucault (2004), a partir da modernidade, há um claro deslocamento de uma estética da existência, que se organizava como arte, um cuidado da vida (a vida como forma apolínia de viver, a busca do ser), para um cuidado que referencia a saúde biológica ou física.

Foucault (2004) lança um olhar para a Antiguidade Grega para pensar as formas de práticas de si como experiências de liberdade, influenciado pela ascese grega do cuidado de si, entendida "como, experiência e como prática elaborada que se transforma em experiência" (FOUCAULT, 2004, p. 13). O percurso que Foucault (2004) delineia a partir da Antiguidade Grega aponta a relação entre o cuidado de si e a estética, tendo ainda o cuidado de si como substância ética e mostrando como "certas práticas de si tornam-se um vetor mediante o qual o ser se constitui historicamente como experiência" (ibid).

10 Subjetividade como a maneira pela qual o sujeito faz a experiência de si mesmo em relação com os jogos de verdades e consigo mesmo (FOUCAULT, 2004).

11 Para Foucault (2004), uma ética normativa em que os sujeitos e seus corpos são investidos política e socialmente, como força estatal e como força de trabalho, a partir de discursos e de práticas que se movimentam pelas relações de saber-poder e de estratégias do incitamento, de estimulação, como mecanismo de padronização e controle das condutas. 
Foucault (2004, p. 18) referencia que se trata fundamentalmente de

[...] práticas de si refletidas e voluntárias através das quais os sujeitos não somente se fixam regras e condutas, como também procuram se transformar, modificar-se em seu ser singular e fazer da sua vida uma obra que seja de certos valores estéticos e responda a certos critérios de estilo.

As técnicas do trabalho sobre si mesmo surgem como lugar de uma experiência, de ensaios do existir. No entendimento de Foucault (2004), os gregos "inventam" os sujeitos como derivados de uma subjetivação a partir da existência estética na relação consigo como regra facultativa de um sujeito livre. Dessa forma, ao compor uma história das práticas de si, Foucault (2004) põe em destaque o sujeito na articulação do governo de si com relação ao outro, como princípio de agir.

O cuidado de si e sua proteção são da esfera das decisões, das escolhas e das responsabilidades livremente exercidas pelos sujeitos. Foucault vê a liberdade correlacionada com a aplicação dos dispositivos de segurança, pois estes geralmente atuam e operam em condições de liberdade. ${ }^{12}$ A liberdade, como descreve Candiotto (2012), é identificada como efeito das ações, que podem tanto limitar o campo de possibilidade de outras ações quanto não se deixar determinar inteiramente por elas.

Para Foucault (2008), não existe a liberdade em si, mas práticas de liberdade que produzem modos de governar-se, como também de limitar e resistir ao governo do outro. Para ele, o cuidado de si é a arte de gerir e delimitar o campo de possibilidade do exercício da liberdade ao absorver a questão do cuidado de si tomado como correlativo da liberdade, que se dá a partir da ética da escolha de modos de ser. Segundo Foucault (2008), a liberdade é da ordem das experiências, da experimentação; Assim os sujeitos tomando a si mesmos como prova, inventam os caminhos e escolhas.

Quando problematizada sob a luz do pensamento foucaultiano, a palavra "Iiberdade" evoca sentidos diversificadamente diferentes enquanto uma prática cotidiana eticamente expressa nos modos de "autoformação" exercidos pelos sujeitos. O autor, por um lado, a destitui do caráter utópico que se Ihe atribui normalmente; por outro, a ideia tão almejada de ser livre parece muito mais próxima de cada um de nós. Para Foucault (2003b), portanto, a noção de liberdade praticada eticamente relacionava-se à maneira de cada um ser e conduzir-se. É preciso um trabalho de si sobre si mesmo, uma construção processual, paulatina e cotidianamente.

As experiências das práticas de lazer apresentam-se, dessa forma, com um grande potencial para a prática de si, para a intensificação das relações consigo e com o outro, para a vivência de novas formas de sociabilidade, a construção de subjetividades e a prática da liberdade. Uma vez que se compreende a liberdade, ela se faz, se realiza,

12 Candiotto (2012), a partir das reflexões de Foucault (2004), também afirma: "ser livre não se limita a agir sem impedimentos externos, sem coerção do poder público ou de outra natureza", pois, para Foucault (2004), "inexiste uma liberdade natural do ser humano". 
também seguindo nesse sentido o pensamento foucaultiano, por meio dos cuidados que os sujeitos têm de si.

Nossa pesquisa investiga o modo das experiências das práticas de lazer de mulheres pertencentes ao meio rural. Objetivamos pensar em possíveis práticas de si que se insiram no contexto do nosso tempo e que possam abrigar, no caso, as mulheres rurais para uma ética da liberdade. Por isso, perguntamos: como se dá o exercício do cuidado de si em termos das experiências (vivências) das práticas culturais de lazer?

\section{METODOLOGIA}

Este artigo desdobra-se de uma pesquisa de campo aprovada pelo Conselho Nacional de Pesquisa (CNPq) do Brasil, desenvolvida entre dezembro de 2012 e dezembro de 2014. ${ }^{13} \mathrm{~A}$ pesquisa de campo dá-se na Região do Planalto das Missões do Estado do Rio Grande do Sul, especificamente na Região Noroeste, pertencente ao Território da Cidadania do Noroeste Colonial. Escolhemos realizar o estudo em Jóia-RS, uma vez que esse foi um dos municípios brasileiros que tiveram o maior aumento na população rural ${ }^{14}$ nas últimas duas décadas, em consequência de oito assentamentos. Conforme dados do IBGE (2013), a população total do município de Joia é de 8.331 , com a população rural perfazendo $74,9 \%$, num total de 6.158 pessoas, e a população urbana chegando a $25,1 \%$, num total de 2.219 pessoas. ${ }^{15}$

Procedemos à seleção das entrevistadas a partir de uma percentagem de inquéritos em função da variação populacional de cada assentamento. Na sequência, fixamos cotas considerando a idade das mulheres. A posição etária/geracional é um dos fatores de organização social, classificação dos indivíduos e dos grupos. Entendemos que a posição de idade afeta homens e mulheres de forma diferenciada (definidos em termos de gênero como construção cultural). Pensamos que há uma especificidade da condição geracional que enseja também relações, situações e representações distintas.

Dentro de um universo grande de sujeitos contemplados pela pesquisa, neste texto, optamos por trazer os discursos (depoimentos, falas) de mulheres ${ }^{16}$ na faixa etária de 50 anos de idade em diante, um grupo populacional pouco estudado como foco de pesquisas com recortes dos estudos de gênero no Brasil, como afirma Brito da Motta (2011). Esta autora destaca que as mulheres, sobretudo as de idades mais jovens e medianas, geralmente

13 Aprovada no edital MCTI/CNPq/SPM-PR/MDA No 32/2012.

14 Nessa perspectiva, estudamos o meio rural não como conceito fechado e estático, mas aberto, dinâmico, polissêmico. Destacamos que não existe um "rural" no Brasil, mas sim "rurais", ou melhor, ruralidades, que são representações de formas de vida que constroem e significam identidades múltiplas ao se constituírem por elementos diversos (MOREIRA, 2005). O rural é uma categoria histórica que, logo, se transforma. Locatel (2004) percebe o rural no âmbito da emergência de uma nova ruralidade possibilitada pelas tecnologias, meios de comunicação e processos mais amplos de escolarização.

15 É uma cidade que se destaca no estado por acolher oito assentamentos agrários. O Núcleo Operacional de Joia é composto por: Barroca, Ceres, Rondinha, Novo Amanhecer, Santa Tecla, Trinta e Um de Maio, Tarumã/Vinte e Cinco de Novembro e Simon Bolívar, compreendendo em torno de 704 famílias assentadas.

16 Tomamos aqui a categoria mulheres heterogênea, multifacetada, plural, uma vez que se produz a partir de diferentes marcadores sociais, como idade, geração, estado civil, classe social, religião, etnia. 
são mais estudadas pelas producões científicas brasileiras. Ela afirma que grande parte das políticas sociais básicas brasileiras é pensada e voltada às faixas etárias jovens e medianas, esquecendo-se as mulheres mais velhas e as vulneráveis. ${ }^{17}$

As gravações foram transcritas e depois sistematizadas e analisadas no presente artigo. Dada a necessidade de condensar informações, são usadas as relativas ao tempo livre e cuidado de si. Como elemento fundante das análises aqui erigidas, utilizamos como tipologia a pesquisa de caráter qualitativo. Depois desse inquérito inicial, compomos uma entrevista em profundidade a partir de blocos temáticos: características sociodemográficas das mulheres e da família; trajetória até chegar aos assentamentos; forma de deslocamento; uso do tempo livre e de lazer; e cuidado consigo.

Aproximamo-nos da ação metodológica a partir das contribuições de Foucault $(2000,2006)$ relativas ao discurso. Os discursos (depoimentos, falas, expressões) narrativos compõem o material empírico produzido para análise nesta investigação. Buscamos capturar os discursos produzidos e vinculados às experiências das práticas de lazer. Olhamos e analisamos as entrevistas tomando-as como depoimentos ou falas enquanto lugar de produção discursiva. Visamos inicialmente a compreender o modo de funcionamento, os princípios de organização e as formas de produção social dos sentidos discursivos (FOUCAULT, 2004). A partir dessa perspectiva foucaultiana, procuramos situar os pressupostos que carregam os discursos, as relações de saber-poder que os estruturam, as estratégias com que se relacionam, as questões que são ignoradas e invisibilizadas e as propostas que se colocam a partir dos enunciados de falas.

A análise de discurso a partir de Foucault (2000) é uma linha de investigação que toma os depoimentos (falas) por objetos-textos, que são nomeados como discursos ao mesmo tempo. Os discursos são "efeitos de sentidos" (FOUCAULT, 2000). Os depoimentos são textos, o que possibilita que sejam tomados em análise do discurso e em um quadro de referência conceitualmente organizado, mas metodologicamente aberto. Desse modo, ouvimos com atenção as mulheres: o que dizem e como dizem. Os textos-entrevistas, como objetos de compreensão dos sentidos na tarefa, devem existir para entender como os discursos narrativos funcionam: que lógica os movimenta, que elementos são repetidos e silenciados, onde esse discurso tem lugar, que posições de sujeito são ocupadas, como os atores se movimentam nessas posições definidas, quem fala, que espaços ocupa (FOUCAULT, 2000).

De acordo com Foucault (2003a), estudar os discursos é analisar sua economia interna, detectar os sistemas de correlações funcionais pela comparação de discursos, descrever suas transformações. É procurar as tecnologias intrínsecas, as estratégias de

17 São as que exercem os papéis mais dinâmicos ou mais esperados socialmente - sejam os profissionais contemporâneos, em novos postos no mercado de trabalho, sejam os familiares de sempre, que compõem a ainda idealizada família nuclear - em políticas como as de acesso às práticas educacionais; a atenção em saúde, com as campanhas governamentais sempre voltadas para as faixas de idade reprodutiva; a atenção ao cada vez mais visibilizado problema da violência contra a mulher. No caso no Brasil, temos um contraponto em políticas públicas, pois não há só de lazer, sendo nomeadas como de lazer/esporte. As políticas de esporte têm força mais expressiva. Nessas poucas políticas, não temos um endereçamento às mulheres, mas geralmente às famílias. São ainda parcas as políticas de lazer endereçadas às mulheres vulneráveis, e quase não há investimentos nesse sentido. 
funcionamento, as táticas que eles instauram, os efeitos de saber-poder que os sustentam e os veiculam. Ainda, é compreender a relação entre as práticas discursivas e sociais e os saberes-poderes que as permeiam.

Estudar, destacar e pontuar os sentidos que existem nos próprios discursos; percorrer os diversos procedimentos que os cerceiam; apreender seu domínio - o que interessa aqui são as experiências de lazer das mulheres: como se construíram, por quais estratégias, como se afirmaram. Nos termos foucaultianos, interessa discutir a vontade que as conduz e a intenção estratégica que sustenta as experiências de lazer.

Buscamos como "pano de fundo" os processos pelos quais o cuidado de si e as práticas de si conseguem chegar às mais tênues e individuais das condutas de mulheres e homens, constituindo suas subjetividades, afetividades e relações. Nesse sentido, tomamos os discursos das mulheres rurais, identificando como soam para elas as formulações do lazer ou como soa o cuidar de si, o ocupar-se de si. As ações de cuidado dão-se por práticas, compreendendo as experiências de práticas de si.

\section{Experiências de lazer: a primazia é cuidar do outro}

Como argumento central das análises, tomamos inicialmente a questão do cuidado de si. Tensionamos a questão do cuidado de si das mulheres a partir do movimento de voltar seu olhar para si, examinando as próprias histórias de sua existência. A expressão "cuidado de si", como nos ensina Foucault (2004), refere-se a um conjunto de experiências; dentre elas, escolhemos explorar e/ou tensionar as experiências de lazer.

As experiências de lazer são, de certo modo, um estar no mundo, com práticas de si, práticas de ações. Compreendemos as experiências de lazer como princípio do aprendizado e estímulo de "conteúdos culturais, com os quais nos modificamos, nos purificamos, nos transformamos e nos transfiguramos" (FOUCAULT, 2008, p. 8).

O cuidado de si implica reflexão sobre o modo de vida, sobre a maneira de regular a conduta, de fixar para si mesmo os fins e os meios. Conforme Foucault $(2008$, p. 14), trata-se da "arte" de governar a si. Essa arte, para o autor, "implica dobrar as forças sobre si, numa relação consigo mesmo", demandada pelo outro.

As entrevistadoras ${ }^{18}$ inicialmente convidavam as mulheres pesquisadas a centrar-se, de alguma maneira, sobre elas mesmas e a dirigir-se ou voltar-se para si. Perguntávamos: é possível identificar o cuidado de si a partir das experiências de lazer como um valor para essas mulheres? Como as experiências de lazer auxiliam as mulheres na busca do cuidado de si?

No conjunto das questões, após criar certo clima de integração, lançávamos o questionamento: como as mulheres se relacionam (ou não) com as experiências de lazer? Seguem aqui alguns recortes discursivos como respostas à pergunta.

18 Reconhecemos aqui as contribuições do material das bolsistas do CNPq, Cauana Peyrot, Emanuely Fontana e Tatiana Trevisan, a quem damos crédito. 
Maria (62 anos) diz: "Lazer!!? O que você quer dizer (ou perguntar) com isso? O que eu vou dizer? Olha, eu, pouco... Não entendo mesmo isso".

Salete (54 anos) diz: “Hummm! Lazer?! Ué, não sei se tenho essa experiência de viver. Hummm! Deixe eu me lembrar! Hummm..." [sinal negativo com a cabeça].

Dalila (57 anos) declara: "Olha, menina, o que eu vou te dizer... Aqui a gente não tem muita opção, não tem mesmo... Nem sei como é... [risos]... Até queria saber e ter, mas não tenho... Olha, o lazer... Eu acho que seria bem importante a gente tirar umas horas para lazer, para brincadeiras, dialogar mais com as vizinhas, passear mais, tirar um tempo até para sentar na poltrona, tomar o chimarrão... Mas pouco faço isso, não me dou esse luxo".

Delama (57 anos), mais descontraída, diz à entrevistadora: "Tu estás perguntando se a gente se diverte, brinca? O que eu vou dizer... Não. De que jeito? Não tenho tempo para isso".

Helena (57 anos): "Só para tu veres, eu agora que pude, com 57 anos, comprar uma boneca". A entrevistadora diz: "Uma boneca?". "Sim, uma boneca. Quando era pequena, eu não pude ganhar. Imagina! Nem uma boneca eu ganhei na minha vida! Quem dera brincar...". A entrevistadora diz: "Que legal! E agora vais brincar?". Ela ri [não confirma] e diz: "Vou colocar no meu quarto, na minha cama".

Podemos perceber, nos dispersos cruzamentos discursivos, que para essas mulheres é difícil falar em lazer. Refletir sobre o lazer delas abre um leque de perspectivas que se relacionam com sua vida, com seus meios e com o significado social e possíveis articulações como modo de cuidar de si. Aprendemos com Foucault (2004, p. 12) que o "cuidado de si somente pode ser experimentado como tal, [...] como uma experiência ético-moral, uma experiência sempre singular e intransferível".

Para essas mulheres nessa faixa etária, a expressão "lazer" parece que soa ainda de forma confusa, distante, como uma experiência que pouco se viveu. Aos poucos, começamos a compreender o quanto as definições discursivas simplificadas de lazer, descritas por essas mulheres como um pedido, talvez, de mais informações, significam um determinado desconhecimento e certa falta dessa experiência e de oportunidades para tal. Maria de Lurdes (62 anos) pergunta à entrevistadora:

"Vê se eu entendi: lazer é um direito?". A entrevistadora diz: "É um direito que todos temos". Maria de Lurdes repete: "Direito? Hummm... É bom saber. Mulheres velhas têm também direito de lazer? Não é só para a piazada, para a gurizada?".

Entendemos que esse tensionamento entre as entrevistadas frente aos questionamentos das entrevistadoras possa ajudar inicialmente as mulheres ao menos a se inquietarem com tal condição. No curso Hermenêutica do Sujeito, Foucault (2010) destaca que o cuidado de si designaria uma tensão agonística, um princípio de inquietação, de pôr o sujeito 
em movimento. A provocação das entrevistadoras tem a finalidade de evidenciar formas do exercício de liberdade. Como lembra Foucault, trata-se de saber, simplesmente, que "sempre podemos ser outros, para podermos talvez estranhar nossa posição (lugar) atual".

Com efeito, o cuidado de si coloca ênfase no exercício crítico da liberdade do indivíduo. Para Foucault (2004), é pelo exercício crítico da própria liberdade que o indivíduo se constitui como sujeito ético, como sujeito moral, e avalia as suas próprias ações. Em Foucault (2004), a autoconstituição do sujeito dá-se por meio da prática refletida da liberdade. Para o autor, o sujeito não nasce pronto; ele se constitui enquanto tal na relação com os outros. Nessa perspectiva, a liberdade está ligada, essencialmente, ao outro, aos outros. Ninguém, para Foucault (2004), "torna-se livre sozinho": a liberdade é uma construção social e, como construção, envolve a presença do outro. Ainda, para Foucault (2004), é à medida que me construo socialmente que aprendo a ser livre para cuidar de mim.

O que nos chama a atenção a partir de um conjunto de entrevistas é que muitas das mulheres têm determinada clareza de grande parte dos direitos que as assistem, como declarou Delama (57 anos):

"A vida agora está boa, temos, como mulheres, muito mais direitos, direito a muita coisa a que nossas bisavós não tinham, como a educação, como poder escolher quantos filhos (controle da natalidade), o acesso a financiamento, a escritura da terra conjunta, a aposentadoria de trabalhadora rural... Hummm... A lei Maria da Penha". ${ }^{19}$

As mulheres em questão estão vacilantes quanto ao direito ao lazer, como é possível observar nos depoimentos. O lazer, desde 1988, é um dos direitos sociais assegurados no artigo $6^{\circ}$ da Constituição da República Federativa do Brasil, ao lado de saúde e educação.

Para Foucault (2004, p. 79), o cuidado de si "concerne de fato, a toda uma prática de si". O autor não toma o cuidado de si e as práticas de si como sinônimos um do outro. O cuidado de si "refere-se à forma de ocupar-se consigo mesmo, em atitudes, são, em si, formas de viver que caracterizam o cuidado de si". Para ele, as práticas de si dizem respeito a todos os procedimentos que possibilitam esse cuidado. Desse modo, o princípio do cuidado de si emerge como fim privilegiado das práticas de si, que são significadas em experiências de si.

De acordo com Foucault (2000), as práticas de si são experiências que determinam o cuidado de si. Embasados nesse aporte foucaultiano, lançamos outra pergunta às mulheres: quais são as experiências que nomeiam como de lazer?

“Eu quase não me dou esse tempo de lazer. Mais são os filhos que têm. A gente fica na propriedade... A gente diz: eles são mais novos e têm que aproveitar a vida". (Edi, 57 anos)

19 A Lei 11.340/06, conhecida como Lei Maria da Penha, ganhou esse nome em homenagem a Maria da Penha Maia Fernandes, que por 20 anos lutou para ver seu agressor preso. Aplica-se à violência doméstica que cause morte, lesão, sofrimento físico (violência física), sexual (violência sexual), psicológico (violência psicológica) e dano moral (violência moral) ou patrimonial (violência patrimonial). 
"Nas minhas poucas horas de folga, eu procuro estar com a família (esposo, filho). To-
mamos chimarrão com a família. É uma forma de viver meu lazer". (Evania, 63 anos)

"Eu não tenho tempo sobrando para mim. Além dos meus filhos, marido, tenho os velhos (meus sogros), a quem eu tenho que dar atenção. Até televisão, pouco assisto, de tão cansada que fico. Eu não divido os cuidados da minha casa com ninguém". (Evania da Silva, 63 anos)

"Meu marido e meu filho vão jogar futebol, mas eu vou visitar a minha mãe, meus netos, e às vezes aproveito e visito os doentes da comunidade". (Lurdes, 56 anos)

"Meu lazer é cuidar dos netos, do marido, da família". (Nanci, 53 anos)

“Eu não tenho esse luxo de lazer, de cuidar de mim. Hoje a gente escuta que o lazer é importante, a atividade física também, mas é difícil achar tempo para a gente. Meus filhos, minhas noras, meus netos [...] dependem de mim, de muitos cuidados $[\ldots]^{\prime \prime}$. (Ivete, 56 anos)

Como observamos nesses recortes discursivos, de um modo geral, há a dificuldade de autofinalização de experienciar práticas de si nas mulheres. O tempo livre e/ou de lazer dessas mulheres pesquisadas está condicionado, afirmado na programação da vida de outros: netos, filhos, noras, cônjuge, pais, sogros. Dessa forma, seu tempo de lazer, quando existe, acaba sendo absorvido pelas necessidades do outro. Parece que as mulheres têm a vida dos outros (ou corpo dos outros) como fonte de cuidado.

Rebeca Abrams (2001, p.121) destaca a tendência e facilidade das mulheres diante do "ato de cuidar do outro", o que denomina de deslocamento. Para a autora, as mulheres têm uma facilidade de "deslocar sua atenção e interesse de si mesmas para a vida e necessidades do outro", deixando, muitas vezes, que os demais ocupem um espaço central em sua vida. Parece que grande parte das mulheres entrevistadas transforma, muitas vezes, seu espaço/tempo de lazer em uma extensão, e não em um intervalo da tarefa de cuidar que desempenha o dia todo.

As atividades para as mulheres dessa faixa etária são nitidamente abnegadas (renúncia ascética à própria vontade em função dos outros) em vez de egoístas. Abrams (2001, p. 135) destaca, por exemplo, que a palavra "egoísmo" tem conotações culturais diferentes entre homens e mulheres:

Chame um homem de "egoísta" e, num certo sentido, estará afirmando sua masculinidade: o adjetivo implica determinação, franqueza, ambição - não de todo bom, mas tampouco de todo mau. Chame uma mulher de "egoísta" e estará fazendo um comentário francamente depreciativo sobre ela: o mesmo adjetivo agora subentende maldade, algo fora do natural, abandono do dever.

Desse modo, ser egoísta enaltece a masculinidade, ao mesmo tempo em que representa perda de feminilidade. Para Orbach (2002), em quase todas as classes sociais, o imperativo de cuidar do outro, de servir - dar, partejar, fazer para os outros -, ocupa um lugar central no mapa cultural das vivências das mulheres. 
Foucault (2004, p. 14) traz para o debate que "o papel do Outro é indispensável para a produção de um esboço de si". Para o autor, "o outro é fundamental na constituição estética de si, na figura do mestre, guia, professor [...] amigo". Destaca, porém, que essa relação não se estabelece pela simples obediência, submissão ou renúncia. A relação com o outro que o autor aponta está baseada na invenção, na criação estética de si mesmo. Ao olhar-me no outro, reconheço-me na diferença do outro, não renuncio a mim.

Susi Orbach (2002) alega que as mulheres tendem a valorizar mais as necessidades alheias do que as próprias. O "imperativo de servir" e a renúncia de si historicamente sedimentada parecem também fazer eco para as mulheres estudadas aqui. Talvez isso seja uma das principais razões de muitas terem dificuldades para priorizar e identificar suas próprias necessidades de experiências de lazer e ir atrás delas.

Essas mulheres, hoje idosas, tiveram muito menos oportunidades educacionais e de participação social - inclusive, igualitária - de cuidar de si, de sociabilidades públicas, de usufruir de experiências de práticas de si, do que os homens da sua geração. Por isso, as mulheres da geração estudada relatam que tiveram de "se virar" em tarefas tradicionalmente femininas na produção doméstica, como diz Maria (62 anos): "Eu, na minha vida, nunca me ocupei comigo mesma; minha vida não foi voltada para mim". Perrot (2005, p. 42) ensina que "dizer 'eu' não é fácil para as mulheres, a quem toda uma educação inculcou a conveniência do esquecimento de si mesmas".

Percebe-se, então, a renúncia de si como certa autoanulação de si. Para Ortega (2008), "[...] isso traduz consigo a perda de uma parte de sua liberdade, expressa na substituição do cuidado de si pelo cuidado dos outros". Vale lembrar o que Foucault (2004, p. 268) assevera em relação ao tema:

Em nossas sociedades, a partir de um certo momento - e é muito difícil saber quando isso aconteceu -, o cuidado de si se tornou um tanto suspeito. Ocupar-se de si foi, a partir de um certo momento, denunciado de boa vontade como uma forma de amor a si mesmo, uma forma de egoísmo ou de interesse individual em contradição com o interesse que é necessário ter em relação aos outros ou com o necessário sacrifício de si mesmo. Tudo isso ocorreu durante o cristianismo, mas não diria que foi pura e simplesmente fruto do cristianismo. A questão é muito mais complexa, pois no cristianismo buscar a salvação é também uma maneira de cuidar de si mesmo. Mas a salvação no cristianismo é realizada através da renúncia de si mesmo.

É possível notar que a ideia basilar dos princípios cristãos de viver pelo rebanho e abdicar de si - renúncia de si em favor do próximo - teve (e tem) um efeito maior sobre as mulheres (SCHWENGBER; MEYER, 2011), sobretudo as da faixa etária apresentada aqui. Podemos perceber que a moral cristã, na qual nos constituímos, ao exigir a renúncia de si mesmo, também anula os corpos com suas experiências, inclusive as de lazer.

Abrir mão da dimensão cultural da experiência de lazer, como afirma Marcellino (2002, p. 95), leva a perder uma das dimensões essenciais da vida humana que instauram e constituem formas de "fruir a vida social, marcada pela exaltação dos sentidos e das 
emoções; mistura alegria e angústia, relaxamento e tensão, prazer e conflito, regozijo e frustração, satisfação e expectativa, liberdade e concessão [...]".

Dar destaque ao tema das práticas de si e à relação com o "cuidado de si", tal como é problematizado por Foucault (2004), adquire, na atualidade, um significado político, pois se trata de tensionar essa histórica "renúncia de si", de um grupo de mulheres dessa geração.

Foucault (2004) traz para o debate a tradição greco-romana como contraponto à moral cristã. Destaca que a relação de renúncia de si pode estar equivocada ao apontar que o cuidado de si procede da relação com a comunidade e depende da relação que é desenvolvida consigo próprio, isto é, mostra como os gregos consideravam necessário cuidar primeiro de si - por meio do exercício da autoelaboração e do autogoverno - para o posterior cuidado com o outro. Logo, "somente aquele que consegue cuidar de si está apto para cuidar do outro" (FOUCAULT, 2004, p. 471).

O que chama nossa atenção é que, com a chegada do envelhecimento e juntamente com a aposentadoria, o tempo livre de grande parte das mulheres urbanas, como destacam pesquisas de Britto da Motta (2009) e Debert (2007), é geralmente maximizado. Sendo assim, o período que antes era ocupado por obrigações se transforma em tempo de lazer. No entanto, parece que, para as mulheres rurais, sobretudo para esse grupo, isso ainda não acontece.

Britto da Motta (2009) identifica as "mulheres pivô". O pivô frequentemente é mais que a cinquentona de hoje. É mais comum pensar nas mulheres na faixa etária depois dos 50 anos. Elas geralmente têm o "destino" tradicional de suporte familiar. Britto da Motta (2009) lembra que muito da solidariedade intergeracional existente se realiza às custas do empenho emocional e do trabalho não remunerado das mulheres. Para a autora (2011, p. 10), "realmente não dá para pensar a geração pivô sem pensar no cuidado, no apoio e no papel e posição fundamental das mulheres na função de cuidadora de todos".

Também Ana Maria Goldani (1999, p. 82) critica "[...] uma continuada discriminação em que a mulher, sobretudo as mais velhas são vistas como dependentes da família, quando, na verdade, elas cumprem, cada vez mais, a função de cuidadora de todos". O que destacamos aqui é que as mulheres dessa geração, consideradas como pivô, abrem mão não só de suas experiências de lazer, mas de outras dimensões da vida, pois as gerações dos/as filhos/as e netos/as têm necessitado do apoio da família em várias circunstâncias, entre elas: precariedade dos empregos, dissolução dos casamentos e o fato, também importante, de que essas mulheres são as primeiras gerações com proventos de aposentadoria de trabalhadoras - no caso estudado, rurais -, que, apesar de escassos, quase sempre são partilhados.

A espoliação financeira ${ }^{20}$ das mulheres velhas tem sido muito comum no Brasil. Adicionalmente, uma parte dessas mulheres toma conta dos/as netos/as para as filhas estudarem, trabalharem, profissionalizarem-se (BRITTO DA MOTTA, 2009). Alda Britto da Motta (2009, p. 5) destaca o apoio das "mulheres dessa faixa etária (mulheres pivô) 
como significativo na contemporaneidade". Em decênios anteriores, as mulheres - mães ou filhas - não estudavam e trabalhavam massivamente fora do âmbito doméstico. As transformações têm cabido às mais jovens. As mais velhas cuidam (Britto da Motta, 2009). Um problema adicional à vista, como diz Britto da Motta (2009), vai ficando para mais adiante no tempo: no futuro, em que quase todas as mulheres das várias gerações poderão estar estudando e trabalhando, a quem recorrerão para cuidar?

Nosso investimento analítico não se propõe como conclusivo e explicativo. Longe de concluir, busca,isso sim, manter aberto o diálogo sobre essa problemática e dar abertura e contribuição ao debate. Encerramos com a pergunta: como direcionar políticas de cuidado de si às mulheres rurais, sobretudo, às mais velhas? Não há como ficar indiferente.

\section{REFERÊNCIAS}

ABRAMS, Rebeca. Jogo de Cintura: Como as Mulheres Podem Conciliar Lazer e Trabalho.

São Paulo: Rosa dos Tempos, 2001.

BRASIL. Constituição Federal de 1988. . Lei Maria da Penha. Lei N. ${ }^{\circ} 11.340$, de 7 de Agosto de 2006.

BRITTO DA MOTTA, Alda. Personagens geracionais na família contemporânea: centenários e pivôs. Congresso Brasileiro de Sociologia, 14. Anais... Rio de Janeiro, 2009.

. As velhas também. Ex aequo, Vila Franca de Xira, n. 23, 2011.

CANDIOTTO, Cesar. Cuidado da vida e cuidado de si: sobre a individualização biopolítica contemporânea. Dissertatio, n. 34, p. 469-491, 2011.

. A governamentalidade em Foucault: da analítica do poder à ética da subjetivação.

O Que Nos Faz Pensar?, n. 31, fev. 2012.

CORBIN, Alain. História dos tempos livres. Lisboa: Teorema, 2001.

DEBERT, Guita G. A invenção da terceira idade e a rearticulação de formas de consumo e demandas políticas. In: Revista Brasileira de Ciências Sociais, vol. 12, n. 34, São Paulo, 2007.

DUMAZEDIER, Joffre. Lazer e cultura popular. São Paulo: Perspectiva, 2001.

ELIAS, Norbert. O processo civilizador. Rio de Janeiro: Jorge Zahar, 1993.

FOUCAULT, Michel. Em defesa da sociedade. São Paulo: Martins Fontes, 1999.

. Governo dos vivos. Rio de Janeiro: Graal, 2000.

. Estratégias de poder-saber. Rio de Janeiro: Forense Universitária, 2003a.

. Foucault estuda a razão do Estado. Ditos e Escritos IV, Rio de Janeiro: Forense

Universitária, 2003b.

. A ética do cuidado de si como prática da liberdade. In: FOUCAULT, Michel. Ditos

e escritos V. Rio de Janeiro: Forense Universitária, 2004. P. 264-287.

. Microfísica do poder. Rio de Janeiro: Graal, 2006.

. Segurança, território, população. São Paulo: Martins Fontes, 2008. 
. A hermenêutica do sujeito (Resumo dos Cursos do Collège de France/1970-1982). Rio de Janeiro: Zahar, 2010.

FIMYAR, Olena. Governamentalidade como ferramenta conceitual na pesquisa de políticas educacionais. Educação e Realidade, vol. 34, n. 2, p. 35-56, maio/ago. 2009.

GOLDANI, Ana Maria. Mulheres e envelhecimento: desafios para novos contratos intergeracionais e de gênero. In: CAMARANO, Ana Amélia (org.). Muito além dos 60 - os novos idosos brasileiros. Rio de Janeiro: Ipea, 1999. P. 75-115.

HUIZINGA, Joan. Homo ludens: o jogo como elemento da cultura. São Paulo: Boitempo, 2007.

IBGE- Instituto Brasileiro de Geografia e Estatística. Portal Cidades. http://cidades.ibge.gov. br/xtras/home.php, 2013.

ORBACH, Susie. Bodies. London: Press, 2002.

LARROSA, Jorge. "Tecnologias do eu e educação". In: SILVA, Tomaz Tadeu (org.) O sujeito da educação: estudos foucaultianos. Petrópolis Vozes, 2000.

LOCATEL, Celso. Agricultura e ruralidade: uma abordagem. Modernização da agricultura, políticas públicas e ruralidades: mudanças e permanências na dinâmica rural das microrregiões de Jales e de Fernandópolis. 2004. Tese (Doutorado) - Unesp, Campus de Presidente Prudente, São Paulo, 2004.

MARCELLINO, Nelson Carvalho. Estudos do lazer: uma introdução. Campinas: Autores Associados, 2002.

MOREIRA, Roberto José (org.). Identidades sociais, ruralidades no Brasil contemporâneo. Rio de Janeiro: DP\&A, 2005.

ORTEGA, Francisco. O corpo incerto: corporeidade, tecnologias medicas e cultura contemporânea. Rio de janeiro, Garamond, 2008.

SANT'ANNA, Denise. O prazer justificado: história e lazer (São Paulo 1969/1979). São Paulo: Marco Zero; MCT-CNPq, 1994.

SCHWENGBER, Maria Simone Vione; MEYER, Dagmar Estermann. Discursos que conformam corpos grávidos: da medicina à educação física. Cadernos Pagu, (36), janeiro-junho, p. 283-314, Campinas - SP, 2011.

PERROT, Michele. As Mulheres ou os silêncios da História. Bauru, SP: EDUSC. 2005.

Recebido em: Junho/2017

Aprovado em: Março/2018 